\title{
Care for all
}

William Yule

Individual and Community Responses to Trauma and Disaster: The Structure of Human Chaos. Edited by R. J. Ursano, B. G. McCaughey and C. S. Fullerton. Cambridge University Press: 1994. Pp. 422. £60, $\$ 89.95$.

A New Species of Trouble: Explorations in Disaster, Trauma, and Community. By Kai Erikson. Norton: 1994. Pp. 263. $\$ 28.99$, £17.95.

As our television screens are once again filled with horrifying pictures of a stricken roll-on, roll-off ferry lying at the bottom of the sea entombing 900 souls, my thoughts go back to March 1987 when the Herald of Free Enterprise capsized outside Zeebrugge harbour. That disaster affected the lives of a great many survivors and changed my professional life dramatically. From then on, trauma and disaster became part of my everyday life. Before 1980 , mental health professionals had not fully recognized the full extent of human reactions to acute traumatic events. Reactions are now known to include distressing intrusive thoughts about the trauma, avoidance of the associated emotions and physiological arousal to the point of not sleeping or concentrating. But once these predominant features were seen to form a syndrome, and the syndrome was given the fancy label of 'post-traumatic stress disorder' (PTSD), then it was suddenly recognized everywhere.

Not surprisingly, sceptics wondered where the syndrome had been during the world wars or when the Titanic sunk. Others began to mock the flood of 'disaster counsellors' who suddenly appeared as if from nowhere. So are we over-diagnosing conditions that, if left to themselves, would remit spontaneously? Are normal stress reactions being unduly medicalized?

These two volumes go a long way to exploring these issues and summarize important findings from the past decade

\section{Autumn Books}

Next week's issue contains Nature's Autumn Books supplement. Reviewers include Hans A. Bethe on David Holloway's Stalin and the Bomb, P. W. Anderson on Roger Penrose's Shadows of the Mind, Stuart Sutherland on Antonio Demasio's Descartes' Error, J. L. Cloudsley-Thompson on Edward 0 . Wilson's autobiography Naturalist, W. F. Bynum on Adrian Desmond's Huxley, Richard DavenportHines on Robert Rhodes James's Henry Wellcome, Adam Kuper on Pat Shipman's The Evolution of Racism, R. V. Short on Carl Djerassi's collection of essays From the Lab into the World and Harvey Brooks on Alan Bromley's memoirs The President's Scientists.

\section{IMAGE UNAVAILABLE FOR COPYRIGHT REASONS}

Trauma of disaster - the ferry Herald of Free Enterprise, which capsized outside the Belgian port of Zeebrugge in 1987, leaving 94 people dead and 405 survivors.

and more. The contributors to the multiauthored book come mainly from the armed forces. The military has been aware for decades that personnel under stress can react badly and has developed firstaid techniques for keeping them fit for action. In times of relative peace, many countries put their military mental-health specialists at the disposal of civilian authorities to help with natural and manmade disasters. This seems a costeffective way of using scarce resources and one that ought to be used more widely. It is good that the authors can share the results of military research with the international scientific community.

There are many important messages in these well written contributions. Bodyhandlers need training to prevent distress. Training, or 'stress inoculation', reduces adverse reactions and would be of help to all emergency workers. Today's "Critical Incident Stress Debriefing", which involves talking people through the incident, clarifying what actually happened and educating them about normal psychological reactions to such events, was used during the Second World War and is effective as a secondary prevention method for emergency personnel. Effective social support for primary victims clearly provides most survivors with some protection against full-blown PTSD.

Chapters concentrate on a wide range of disasters from natural ones such as floods or earthquakes through manmade ones such as Chernobyl to the experiences of people on board a Gulf War hospital ship. The picture is inexorably built up that the more a trauma is viewed by the victim as being deliberately caused, and the greater the physical suffering and the threat of death, then the greater the level of distress. There is always an interplay between the actual danger and the subjective interpretation of the threat that determines the level of stress.

Kai Erikson's volume nicely complements this academic, scientific review. $\mathrm{He}$ provides a much more personal feeling of how various communities can be struck by disasters of various types. We learn about the Ojibwa tribe of Canadian Indians who suffered when their fishing rivers were poisoned by mercury from an industrial spillage; citizens of Colorado who discovered that leaked petroleum vapours were invading their houses; and Haitian immigrants who had their savings stolen. Whole communities are seen to be devastated and the effects of disaster are shown to affect more than individuals.

So who needs a caring response? Few will fail to be moved by $A$ New Species and many will be convinced by the arguments in Individual and Community Responses. People are often unable to cope with the overwhelming emotions that hit them unexpectedly when a disaster strikes. We have a good feel for which groups are most vulnerable; we are reasonably certain that early interventions that help survivors to express these emotions save later distress; and we are even beginning to develop a more effective range of interventions for those who do develop PTSD. As we watch the grieving communities in Sweden and Estonia, as we hear the harrowing tales of the few survivors, then we must conclude that we all need a caring response. It should come from the whole community, not only a few mental health professionals.

William Yule is in the Department of Psychology, Institute of Psychiatry, De Crespigny Park, Denmark Hill, London SE5 8AF, UK. 